\title{
An Analysis of the Canadian Mosaic: Language Usage among Immigrant Post-Secondary Students
}

\author{
Julia E. Kiernan ${ }^{1, *}$ \\ ${ }^{1}$ Department of Rhetoric, Writing, \& American Cultures, Michigan State University, East Lansing, Michigan, United \\ States \\ *Correspondence: Department of Rhetoric, Writing, \& American Cultures, Michigan State University, 434 Farm \\ Lane, East Lansing, Michigan 48824, United States. Tel: 1-517-355-2400. E-mail: kiernan@msu.edu
}

Received: May 22, 2014

Accepted: June 9, $2014 \quad$ Online Published: June 16, 2014

doi:10.5430/wjel.v4n2p21

URL: http://dx.doi.org/10.5430/wjel.v4n2p21

\begin{abstract}
This article examines language usage — specifically, multilingualism as a division of multiculturalism—in regard to Canadian post-secondary education. The findings challenge previous research, popular opinion, and government policy, which tend to designate Canadian classrooms and society as accepting of linguistic diversity. While the data situates Canadian students as extremely ethno-linguistically diverse, this diversity is predominantly confined to home communities. This paper uses national population demographics to analyze the limitations of government policy, thereby recognizing this confinement as problematic, and emphasizes ways in which Canadian post-secondary institutions can redesign pedagogical and curricular practices to better engage (and serve) multilingual immigrant students.
\end{abstract}

Keywords: multilingualism; multiculturalism; linguistic pluralism; cultural pluralism; allophone; heritage languages

\section{Introduction}

The analysis of Canadian language histories, policies, and practices outlined in this article is seated in multiculturalism. This narrative of Canadian identity politics uses multiculturalism to describe population demographics in terms of language and language practices. Twentieth-century cultural initiatives based in immigration, which developed into multiculturalist policy and legislature, are used to investigate how the experiences of different language groups in Canada - anglophone, francophone, First Nations, and allophone(Note 1) - have come to be treated in the federal and provincial government's educational initiatives. Specifically, this project offers policy analysis of government legislation regarding minority language education-including distinctions in practices among the various provinces and territories - to not only draw attention to the unique treatment of language in Canada, but to also elaborate upon the shortcomings of these policies in regard to immigrant students who pursue higher education. This paper argues that the diverse linguistic backgrounds of immigrant students is an important site of inquiry due to this population of learners unique ability to negotiate between languages, which is not only a benefit to learning, but also a resource to citizens who are members of a culturally rich and linguistically diverse nation.

Throughout Canadian history, language issues have remained central to national identity and, consequently, dominant in public policy (Bumstead 2008; Williams 1996; Munroe 1979; Bleasdale 1979; Li 2003; Cullen 1979; MacMillian 1998). Canadian multiculturalist legislature accepts that citizens have strong relationships with the country's two founding cultures—English and French—as well as various vibrant non-founding cultures (Bumsted, 2008, p.649). An essential aim of multiculturalism is to avoid assimilation or integration with the mainstream and, instead, work to change the definition of what is mainstream (Williams, 1996, p.161). Simply, these ideologies work to support cultural pluralism, a model wherein citizens are encouraged, by government agencies, to maintain diverse heritage languages and cultures. The current model of pluralism maintains that cultural lines and linguistic policies must exist as dynamic so as to preserve the nation's cultural mosaic, which is often described as uniquely Canadian.

Moreover, 
The history and development of this country is very much the story of successive immigrations and the interaction of these groups with the existing society. How they adapted their way of life to Canadian conditions and influenced Canadian patterns has been and will continue to be one of the determining forces in establishing a Canadian identity and nation. (Munro, 1979, p.12)

As such,

Canadians have prove[n] that while the exercise of rights requires some conformity to community norms it does not necessitate the end of group or individual differences and heritages. (Bleasdale, 1979, p.35)

These quotes are useful starting points in this discussion because they emphasize a normalization of government legislation that recognizes the importance of not only minority language rights, but also the role of difference within the definition of Canadian identity. This difference is often analogized by a mosaic structure, the most simplistic definition of this model is a coming together of discrete objects (e.g. peoples) to create a unified object (e.g. national identity). Ultimately, Canadian acceptance of cultural pluralism is most often exemplified by this mosaic, which boasts that no other country in the world encompasses inhabitants from so many different backgrounds who exhibit strong loyalty towards Canada while still maintaining their immigrant cultural heritage. This paper argues that this cultural heritage is most commonly expressed within multilingual ability.

Nevertheless, official policy, which is committed to pluralism and as such represents a version of multilingualism, maintains diversity by situating languages as separate and discrete. Pluralist tendencies concerning language were first felt in Canada in the mid-1960s when the federal government moved to recognize anglophone-francophone biculturalism and bilingualism as fundamental to the national agenda. In the following decades, the federal government announced multiculturalism as integral to government policy, establishing the Canadian Consultative Council on Multiculturalism in 1973; bringing multiculturalist policy into the Constitution Act in 1982; launching the Canadian Multiculturalism Act in 1988; and implementing multiculturalist policy within the Charter of Rights and Freedoms in 1988 (Williams, 1996, p.157). Primary in all of the government legislation outlined is the facilitation of belonging (both cultural and linguistic). The current federal government maintains that no ethnic group or race is more desirable than another-emphasizing that all cultural groups are essential elements in Canadian identity constructs (Cullen, 1979, p.24) - yet, there are no government programs in place to develop or even maintain this sense of belonging within post-secondary education.

While the legislation itself is progressive, the lack of practical attention to these multicultural linguistic policies fail to foster pride in and maintenance of heritage languages within multilingual immigrant populations. Most research to date (Williams 1996; Bleasdale 1979; Li 2003; Cullen 1979; MacMillian 1998) has explored the failure of multicultural advancement, cultivation, and functionality within society; however, this paper explores how education—specifically higher education—can function as a space wherein multicultural and multilingual learning can be fostered and encouraged. Through a consideration of government legislation regarding minority language education this paper aims to draw attention to the shortcomings of these policies in regard to immigrant students who pursue post-secondary education. Ultimately, analysis of language policy will offer practical curricular initiatives, based within current student demographic data, which will serve to take a proactive stance in the establishment of post-secondary multicultural and multilingual education. This project, with its focus on post-secondary education, aims to explore ways educators can extend Canadian linguistic pluralism that exists within current legislation. A central aim of this paper is to discuss the linguistic tensions that exist within Canadian society and higher education due to the superficial encouragement of diversity within policy; reassessing the potentialities of policy within higher education will position this paper to move beyond the current climate of suppression, and locate linguistic diversity as a resource within post-secondary education.

\section{Description of Problem}

In Canada there are three primary language groups: anglophones, francophones, and allophones. Figure 1 illustrates the national population demographics of these languages in terms of heritage language, or the first language learnt (at home) in childhood and still used. Figure 2 indicates that anglophone populations are dominant in three of four regions of Canada-Pacific Coast, Prairies, and Atlantic Canada. Six of Canada's ten provinces identify as anglophone (Alberta, Saskatchewan, Manitoba, Nova Scotia, Prince Edward Island, and Newfoundland \& Labrador), with one province (Québec) identifying s as francophone. However, Québec's linguistic population, while unique, is comparable to that of New Brunswick, which is recognized as Canada's only bilingual province.(Note 2) This leaves Ontario and British Columbia, the two most heavily populated anglophone provinces, with allophone speakers who 
comprise more than one quarter of the total provincial population. Ultimately, it is only in Central Canada that the nation's linguistic diversity-in terms of the three language communities-is evident. In the remaining regions anglophone Canadians are the majority, with allophone, and then francophone populations following. Figures 2 and 3 illustrate that in the majority of regions allophones make up a large minority, often outnumbering the francophones. This is important to this discussion because allophone languages equate to immigrant languages, and are most often overlooked in post-secondary education.

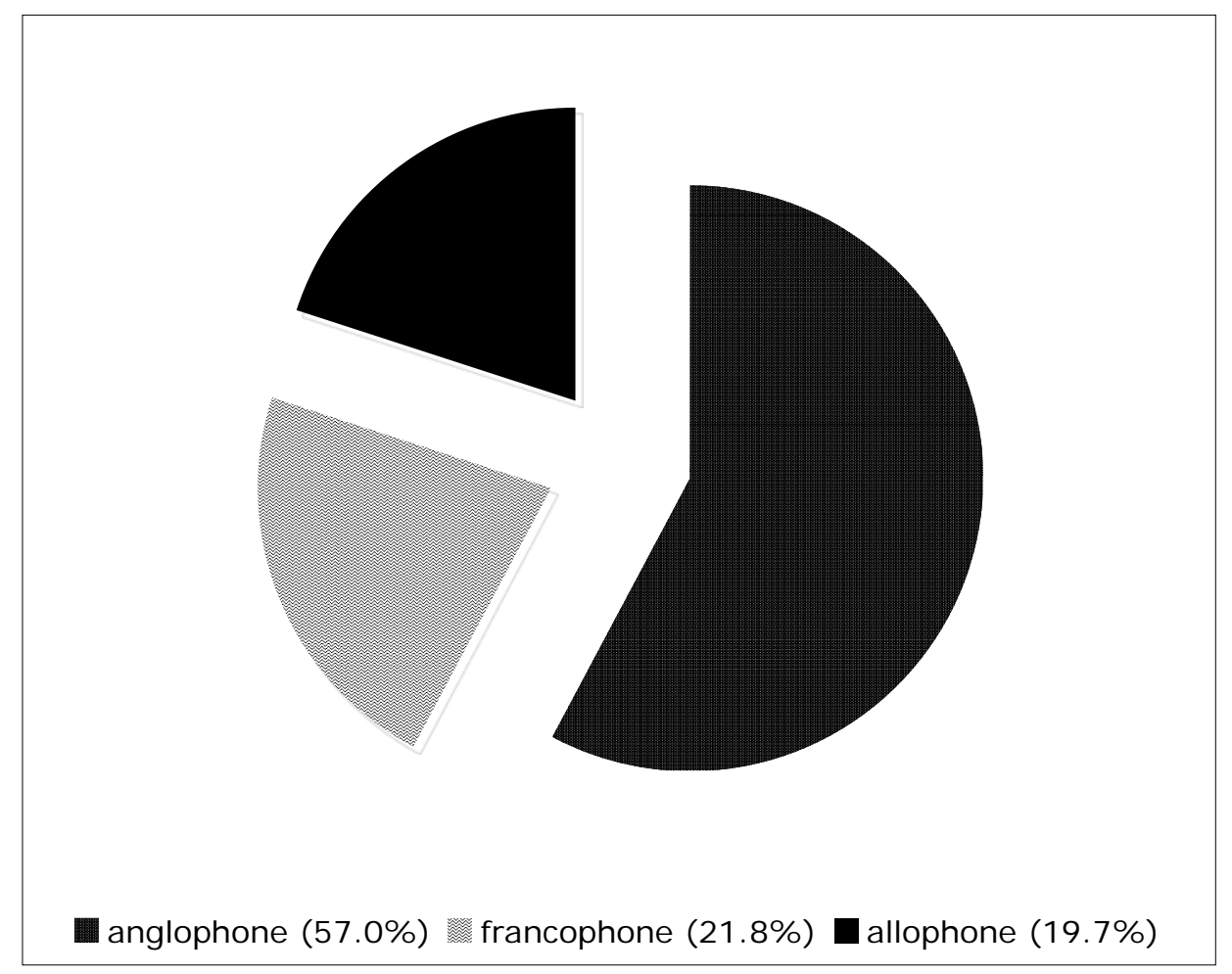

Figure 1. National Language Populations

Linguistic populations differ between the provinces due to distinct regional history, immigration, and population dynamics. Canada's geographic linguistic boundaries are further emphasized by school systems that teach regionally specific curricula. The benefit of regionalized educational systems is that students primarily learn languages that are usable in their daily lives. Students in anglophone provinces learn English almost exclusively, unless parents choose to enroll them in French-immersion or francophone educational programs-the reverse, though unlikely, could also occur in francophone regions. In areas where immigrant languages are high, such as Ukrainian in Saskatchewan and Chinese in British Columbia, there is also a level of language schooling available to primary and secondary school immigrant students. However, the drawback to this method of linguistic education is that Canada's multicultural and multilingual heritage remains regionalized and not recognized nationally. The regionalization of education serves to limit the influences of federal multicultural policy in its lack of a national multicultural standard in education. Canada's regionalized education systems are province-specific; consequently, provinces with low levels of cultural and linguistic diversity can choose to ignore curricula that address issues of multiculturalism-despite national trends-because these issues are not as socially and economically relevant in provinces with low diversity. 


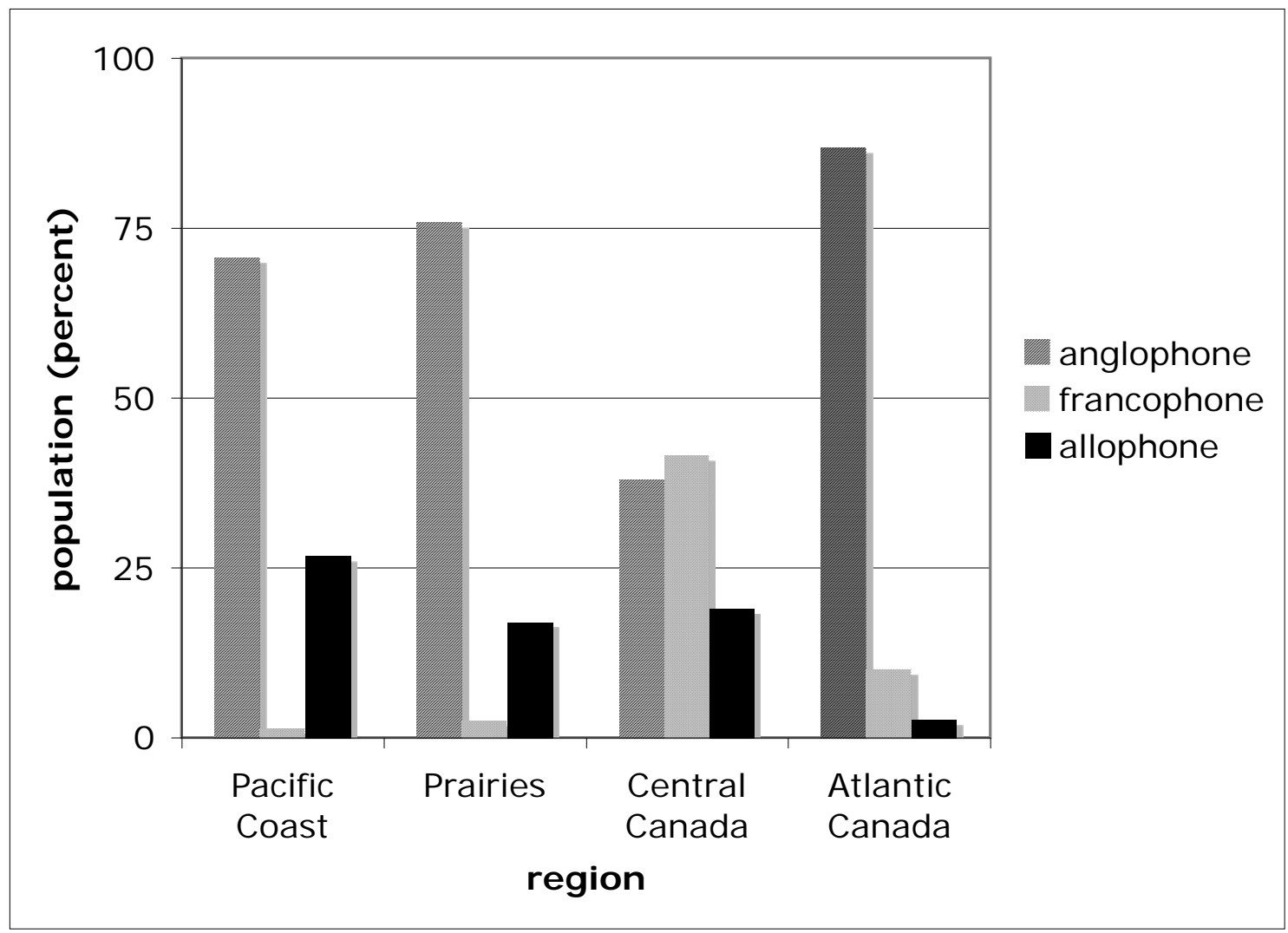

Figure 2. Regional Language Populations

In a country that boasts a multicultural heritage, the lack of attention to linguistic diversity within post-secondary education is an important point of inquiry. Through analyzing this gap in research concerned with Canadian language politics, this paper situates linguistic diversity as an important context for higher education-particularly its allowance for the teaching of effective communication via audience and purpose. Yet, while the Charter of Rights and Freedoms provides that educational institutions should teach students tenets of effective communication; ensuring the continuation of a group's identity through the provision of a socially and culturally stimulating environment (Martel, 1991, p.16), this environment is rarely cultivated. This paper positions that the ability to negotiate between languages is a form of effective communication, and is therefore paramount to the success of immigrant students who live in ethnically diverse communities, particularly when these communities expect the use of both English and one's heritage language for differing cultural situations. Ultimately, education in the usefulness of language negotiation would benefit immigrant students, preparing them to draw upon their diverse cultural and linguistic backgrounds. A classroom based in multiculturalism would, therefore, promote effective communication through encouraging students' consideration of their linguistic and cultural heritage(s). Yet, post-secondary programs do not seem to recognize the merits of developing a multilingual agenda within curricula and feel no real pressure from the federal government to modify existing programs(Note 3), which is a major educational oversight. This project differs from mainstream educational culture in its claim that a central flaw within Canadian education, in terms of linguistic pluralism, is that there is no real call to action in federal legislation to incorporate multicultural and multilingual perspectives within post-secondary systems. 


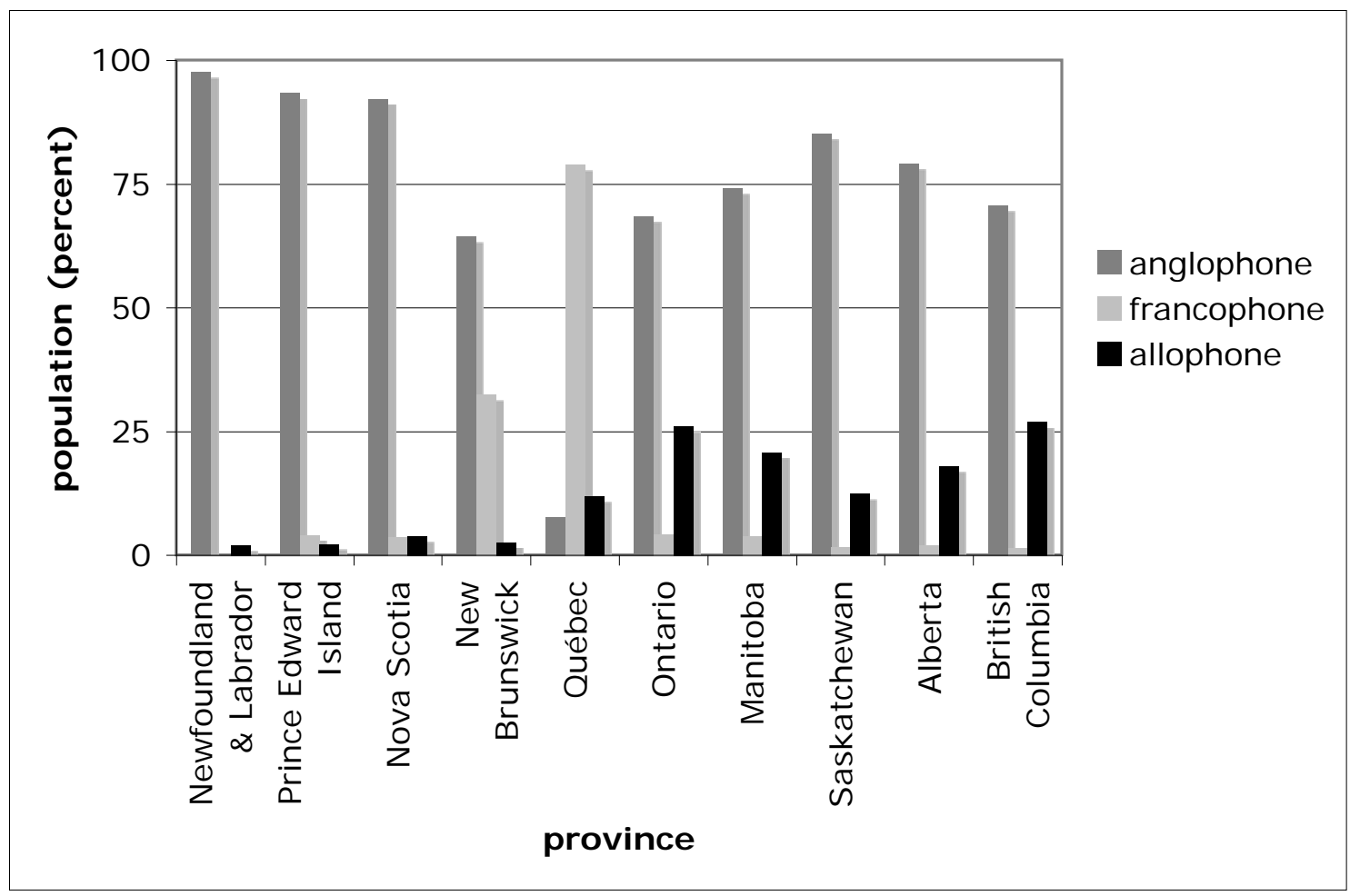

Figure 3. Provincial Language Populations

\section{Analysis of Current Policy \& Practice}

This section analyzes the policies and practices that affect each language group's population both provincially and nationally - paying special attention to immigrant populations. The factors that will be used to discuss policy and practice include a numerical assessment of language groups, the value of language as commodity, a consideration of Canadian linguistic ideologies, as well as a survey of linguistic pluralism in post-secondary education.

Regardless of provincial and federal policies and initiatives that support multiculturalism, the reality faced by linguistic communities is that the greater the number of a language's speakers more powers, rights, and privileges are afforded to its speakers. The data from Figures One, Two, and Three demonstrate that anglophones in Canada are the linguistic majority by nearly two thirds. Canada has been and continues to be anglophone in terms of ancestral origin and linguistic ability. At Confederation, the population was British (60.5\%), French (31.1\%), other European (6.9\%), First Nations (0.7\%), and other (0.8\%) (Minister 6); the statistics collected by a recent Census provide a relatively unchanged linguistic composition, with English (57.0\%), French (21.8\%), allophone languages (19.7\%), and First Nations (0.7\%). Of note, however, is the increase in "other European" or "allophone language" groups; this growth positively correlates with increased immigration to Canada, which has been recorded as steadily rising since the mid-nineteenth century. Thus, while both French and English speakers settled in regions of Canada prior to Confederation, since 1867 there has been and continues to be a significant influx of immigrant, allophone Canadians into the country. Nevertheless, due to the more recent establishment of allophone speakers as Canadian citizens (in relation to anglophone and francophone Canadians who had settled before Confederation), as well as the huge diversity of allophone languages, immigrant languages remain marginalized in Canadian society.

Due to their larger population, English-speaking Canadians enjoy significantly more language rights and privileges than the other four groups. Throughout Canada English is the dominant linguistic force in industry, politics, economy, tourism, etc.

While Canada is recognized internationally as an anglophone-francophone bilingual country, most citizens (and students) do not rely on both languages in their daily lives. The skills of spoken and written bilingualism are practiced in the provinces of Québec and New Brunswick, but because French is an official Canadian language francophone Canadians hold many rights that allophone citizens still struggle towards. What is unique about 
francophone-anglophone bilingualism in Canada is that both languages maintain linguistic rights and institutional language obligations _ other minority language groups do not have a collective right to language (Li, 2003, p.134). And despite the steady rise in allophone populations, francophones maintain linguistic rights and freedoms that have not been granted to allophones.

Lack of attention to language retention and cultural heritage at all levels of education locates allophone languages and histories on the margins_-despite growing populations of Canadian immigrants. This is problematic given that allophone populations in Canada are roughly equivalent to francophones; moreover, allophone populations are also consistently larger than francophones in the Pacific Coast and Prairie provinces. Nevertheless, despite the substantial population of allophones across Canada and the multicultural policies that promote linguistic retention, few immigrant languages have L1 survival rates of fifty percent or better; moreover, first and second generation immigrants show marked differences in their ability to retain heritage languages-as generations increase language ability decreases significantly ( $\mathrm{Li}, 2003$, p.135, Laponce,1996, p.82). Unlike biculturalist and bilingualist federal legislation, which is grounded in preserving the francophone minority's language rights, initiatives that encourage multiculturalism and multilingualism do not protect immigrant heritage language rights (MacMillian, 1998, p.194) or language retention programs (Comeau, 1979, p.40). This is especially problematic in light of the fact that Canada continues to pride itself on the pluralist agenda of the cultural mosaic. Li (2003, p.140) suggests,

There is a danger that Canada could lose its linguistic diversity because of insufficient institutional and social support to preserve non-official languages beyond the first generation of immigrants.

This project's analysis of government policy regarding minority language education examines national immigrant populations in order to argue for post-secondary change, which would better meet the needs of allophone students—needs that are acknowledged, but not necessarily supported by government policies of multilingualism and multiculturalism. Allophones Canadians exist as a minority language group, yet their numbers are significant. Bringing allophone languages into education, via discussion and inquiry would not only be in keeping with Canada's multiculturalist agenda, but would also create environments for students to consider their own linguistic identity and diversity in the context of others.

The fate of minority cultures in Canada is dependent upon language retention. This retention often occurs in the home and in home communities, but is not always a component of public schooling, particularly post-secondary education. The creation of spaces in universities and colleges where heritage languages can be learned and used by students is not only in keeping with federal legislation, but is also incredibly important to language retention in terms of the many identity challenges placed upon students who enter post-secondary education; at this stage in their lives many students have moved away from home and, consequently, are removed from their home language(s). Working under the auspices of the federal government literacy education could be designed as ideal spaces to respect and maintain heritage languages, promoting cultural pluralism as well as acceptance. In the case of allophone Canadians, the presence of bilingual initiatives — and absence of multicultural ones — within the sphere of education essentially works against the preservation of their linguistic identities, pushing these students toward anglophone and francophone assimilation, which leads to allophone language loss. This phenomenon is comparable to "bilingual" education in the U.S., which mandates assimilation to English and suppresses the use of immigrant languages. In many countries there is no room to question such assimilative forces; however, in Canada, a nation that welcomes and encourages diversity, we must question why multiculturalism is not working-or only functioning symbolically - for minority language populations and explore ways in which multiculturalist policy can be used to tangibly benefit these populations.

For instance, government policy has worked to position linguistic and social diversity as a form of cultural capital that promotes the development of Canada as a veritable leader in global relations (Li, 2003, p.142). In efforts to promote multiculturalism, rather than anglophone or francophone assimilation, the government has taken the stance that "multiculturalism creates a greater appreciation of the value of culture and language which works to the benefit of all Canadians in all parts of the country" (Munro, 1979, p.13). Thus we see the government as central in the push towards maintaining a multiculturalist national character within trade relations. Multicultural policy positions linguistic pluralism as a provider of multiple literacies that function in Canada's pursuit of global economics in regard to trade, employment, science and technology, globalization, as well as peace and security. In essence, multiculturalism has become one of Canada's most sought after renewable resources where diversity functions to bridge world marketplaces, positioning Canadians to excel in areas of global commerce, cultural exchange, and political dialogue (Williams, 1996, p.164). Consequently, recognizing and explicitly including anglophone, francophone, and allophone experiences in post-secondary learning would allow the acknowledgement and 
assignment of multiple literacies, providing students with a global way of thinking that would allow them to communicate with diverse audiences, and better prepare them for out-of-school practices of effective communication.

However, the exclusion of allophone language education in higher learning is the norm, and potentially threatening to the learning of effective communication strategies. In Critical Academic Writing and Multilingual Students Canagarajah explores how the linguistic differences multilingual students bring to the classroom can be embraced by instructors and viewed as a resource. Arguing against the long held ideology that students with diverse linguistic backgrounds have strong tendencies to create deficient texts, Canagarajah juxtaposes two methods: the conversion approach and the negotiation approach. The conversion approach, which is commonly practiced in educational settings, calls for home languages to be used in home environments and academic languages to be used in school, Canagarajah does not support this pedadogical paradigm and argues that this method creates either/or binaries and is not inclusive; he, instead, supports the negotiation approach, which allows a meshing of languages and identities. In the negotiation approach home languages are brought into school, interacting as a tool in creating effective communication. Thus, in order to establish allophone sustaining curricula a negotiation approach should be adopted. This approach allows a coming together of multiple worldviews; home languages would be brought into the classroom and classroom languages into the home. This negotiation would allow not only effective communication, but a tangible display of the mosaic structure wherein immigrant languages are viewed as assets and resources to students. Laponce (1996, p.84) suggests that languages need to be given social recognition outside the immigrant community in order to be maintained. Establishing multicultural and multilingual curricula would connect culture to the classroom, thereby recognizing the importance of the outside community as well as providing federally sanctioned multicultural learning programs.

\section{Discussion}

Through exploring Canadian-based relationships between language, cultural, citizenship, and education this project has worked to provide insight into how future post-secondary curricula can effectively recognize and respond to the diverse linguistic cultures of Canada's allophone students. Ultimately, this paper has sought to provide a working description of who Canadian allophone students are and how they are classified in the academy. Through analysing minority language policy in terms of population demographics this strategy can be viewed as successful in its offering of a working description of Canadian allophone students. Ultimately, this project offers a Canadian contextualization of allophone multilingualism, pointing to a classroom environment that prefers language segregation over language interaction and language negotiation. In order to fully assess the value of curricula that favours these latter practices further research must be conducted.

This project also suggests that while anglophone instruction is the lingua franca of the academy, there is room to respond to the diverse linguistic needs and realities of allophone students, which would serve to support the preservation and interaction of our students' and Canadian society's collective and diverse heritages. In regard to this paper's analysis of allophone language usage in current Canadian post-secondary educational practice, reviews of population demographics and published research indicates that Canadian understandings of multilingualism are comparable to mainstream practices in the rest of North America as well as abroad. Simply, Canadian classrooms expect and favour practices of English monolingualism, conforming to ideologies of language segregation. This finding is not startling as it is the academic norm in English-medium post-secondary education worldwide; however, when one considers the high levels of multilingualism and cultural diversity present within Canadian society as well as the many steps the Canadian government has taken to support its multicultural heritage it is somewhat surprising that multilingualism has not, as yet, been considered a resource to post-secondary students. This is particularly of note when one considers the increasing levels of international writing research concerned with multilingualism (Blommaert et al 2005; Canagarajah 2002; Makoni 2003; Matsuda 2006; Matsuda and Silva 1999; Lu 1994; Rassool 2004, etc.) that is occurring in countries other than Canada. Globally, research that embraces and encourages multilingual interaction within education, particularly post-secondary education, is flourishing; yet much of the research on multilingualism and education in Canada focuses on primary and secondary education, or Québécois francophone culture versus national French-English bilingualism (Hayday 2005; Heller 2002, 2007; Taylor 2008). Canadian research must shift to concern itself with the relationships between multilingual allophone populations and post-secondary education - areas of language research underrepresented in current scholarship. Future research must assess how post-secondary institutions can utilize federal policy as a resource to encourage cultural and linguistic diversity. By testing and analysing approaches to multilingualism, particularly those related to language interaction, 
research can provide example and insight into how educators and policy makers can approach and realize the conflicts and struggles that Canadian allophone students face. Ultimately, such scholarship will respond to gaps in international, North American, and Canadian multilingual scholarship.

\section{Conclusion}

This project illustrates that Canadian students maintain high number of ethno-linguistic diversity, but, as demonstrated, this diversity continues to be confined to home environments and communities. Inaccessibility to home languages in government institutions, such as post-secondary education, contributes to immigrant social alienation and fails to recognize the importance of home languages upon greater society (Makoni, 2003). However, there exists the possibility to change the current conditions of Canadian writing classrooms. The research indicates that growing immigrant diversity provides a valid reason to bring multicultural initiatives into the classroom, which will create learning environments to foster the very ideologies of the Canadian government's cultural mosaic.

The notion of bringing immigrant home languages into the classroom responds directly to policies of the Canadian Multiculturalism Act that support the retention of immigrant minority languages. Thus, the introduction of allophone languages into the English-medium classroom would function to uphold the Canadian government's current model of pluralism through offering a practical educational initiative that would potentially preserve the nation's cultural heritage through its valuation of immigrant languages. Moreover, the existence of a policy such as the Canadian Multiculturalism Act would suggest that language variety and moving between languages are constants in all areas of Canadian society. However, students who attend postsecondary institutions in Canada are confined to English. This monolingual expectation works to every students' detriment-monolingual and multilingual alike - in it its failure to recognize that knowledge extends beyond English, recognizing only one language limits student knowledge to one experience, ignoring the many knowledges and knowledge practices at play. Such an approach restricts access to cultural and linguistic knowledge. This project argues that we need to view difference as resource, where students' home languages and cultures become an asset to their linguistic development. Moreover, because the Canadian government's commitment to intercultural community building positions universities and colleges as integral in the creation of linguistic support systems, it is necessary to provide educational spaces where students can draw upon their plurilingual abilities. This project illustrates that the multicultural and multilingual ecology of our Canadian classrooms situates them as ideal sites for engendering student awareness and encouraging multilingual dialogue. However, it is not enough to realize the linguistic potentiality of Canadian society and its education systems; future research must work to implement the government's multilingual policies in post-secondary classrooms.

\section{References}

Bleasdale, T. (1979). Labour's stand on the language issue in Canada. In K. A. McLeod (Ed.), Multiculturalism, bilingualism and Canadian institutions (pp. 32-36). Toronto: Faculty of Education, University of Toronto.

Blommaert, J., Muyllaert, N., Huysmans, M., \& Dyers, C. (2005). Peripheral normativity: Literacy and the production of locality in a South African township school. Linguistics and Education: An International Research Journal, 16(4), 378-403. http://dx.doi.org/10.1016/j.linged.2006.03.001

Bumsted, J.M. (2008). The peoples of Canada: A post-confederation history ( $3^{\text {rd }}$ ed.). Oxford: Oxford University Press.

Canagarajah, A. S. (2002a). Critical academic writing and multilingual students. Ann Arbor: University of Michigan Press.

Comeau, P. (1979). Multiculturalism and bilingualism at the community level. In K. A. McLeod (Ed.), Multiculturalism, bilingualism and Canadian institutions (pp. 37-41). Toronto: Faculty of Education, University of Toronto.

Cullen, J. S.G. (1979). Immigration and Canada. In K. A. McLeod (Ed.), Multiculturalism, bilingualism and Canadian institutions (pp. 23-26). Toronto: Faculty of Education, University of Toronto.

Gentil, G. (2005). Commitments to Academic Biliteracy: Case Studies of Francophone University Writers. Written Communication, 22, 421-71. http://dx.doi.org/10.1177/0741088305280350

Hayday, M. (2005). Bilingual today, united tomorrow: Official language in education and Canadian federalism. Montreal and Kingston: McGill-Queen’s University Press. 
Heller, M. (2002). Globalization and the commodification of bilingualism in Canada. In D. Block and D. Cameron (Eds.), Globalization and language teaching (pp. 47-63). London: Routledge.

Heller, M. (2007). Bilingualism: A social approach. New York: Palgrave Macmillan. http://dx.doi.org/10.1057/9780230596047

Laponce, J. A. (1996). Minority languages in Canada: Their fate \& survival strategies. In A. Lapierre, P. Smart, \& P. Savard (Eds.), Language, culture and values in Canada at the dawn of the $21^{\text {st }}$ Century (pp. 75-88). Ottawa: Carleton University Press.

Li, Peter S. (2003). Destination Canada: Immigration debates \& issues. Don Mills: Oxford University Press.

Lotherington, H., Holland, M., Sotoudeh, S., \& Zentena, M. (2008). Project-based community language learning: Three narratives of multilingual story-telling in early childhood education. Canadian Modern Language Review, 65(1), 125-145. http://dx.doi.org/10.3138/cmlr.65.1.125

Lu, M. Z. (1994). Professing multiculturalism: The politics of style in the contact zone. College Composition and Communication, 45(4), 442-458. http://dx.doi.org/10.2307/358759

MacMillian, C. M. (1998). The Practice of Language Rights in Canada. Toronto: University of Toronto Press.

Makoni, S. (2003). From misinvention to disinvention of language: multilingualism and the South African Constitution. In S. Makoni, G. Smitherman, A. F. Ball, \& A. R. Spears (Eds.), Black Linguistics: Language, Society, and Politics in Africa and the Americas (pp. 132-151). London: Routledge.

Martel, A. (1991). Official language minority education rights in Canada: From instruction to management. Office of the Commissioner of Official Language, Government of Canada.

Matsuda, P. K. (2006). The myth of linguistic homogeneity in U.S. college composition. College English, 68(6), 637-651. http://dx.doi.org/10.2307/25472180

Matsuda, P. K., \& Silva, T (1999). Cross-cultural composition: Mediated integration of U.S. and international students. Composition Studies, 27, 15-30.

Munro, J. (1979). Multiculturalism-the policy. In K. A. McLeod (Ed.), Multiculturalism, bilingualism and Canadian institutions (pp. 12-15). Toronto: Faculty of Education, University of Toronto.

Rassool, N. (2004). Sustaining linguistic diversity within the global cultural economy: Issues of language rights and $\begin{array}{llll}\text { linguistic } & \text { possibilities. } & \text { Comparative } & \text { Education, }\end{array}$ http://dx.doi.org/10.1080/0305006042000231356

Taylor, L. K. (2008). Of mother tongues and other tongues: The stakes of linguistically inclusive pedagogy in minority contexts. Canadian Modern Language Review, 65(1), 89-123. http://dx.doi.org/10.3138/cmlr.65.1.89

Williams, C. H. (1996). Citizenship and minority cultures: Virile participants or dependant supplicants? In A. Lapierre, P. Smart, \& P. Savard (Eds.), Language, culture and values in Canada at the dawn of the $21^{\text {st }}$ Century (pp. 155-182). Ottawa: Carleton University Press.

\section{Notes}

Note 1. An anglophone Canadian is a citizen whose first language is English; a francophone Canadian is a citizen whose first language is French; a First Nations citizen is a member of an indigenous group, with an indigenous first language; and an allophone Canadian is a citizen whose first language is neither English, French, nor a First Nations language.

Note 2. While New Brunswick is identified as Canada's sole bilingual province, Census Canada's linguistic analysis of this province, and all other regions, recognizes language spoken in terms of first language learnt at home, which in New Brunswick is predominantly anglophone (64.4\%) followed by francophone (32.4\%). And while a large population of citizens from this province learn to communicate in both official languages, less than one percent identified as bilingual, in terms of first language spoken at home. Moreover, in each province Canadians who identify as English-French bilingual comprise less than one percent of the population, with the total national bilingual population standing at .3\%.

Note 3. This point is referring to multilingual curricula aimed at resident Canadians, not international students. However, in either case, there is a push for English-Only education rather than programs that move to engage students' diverse linguistic and cultural knowledge assets. 